\title{
Especialidades Médicas - Neurocirurgia
}

\author{
Mario Augusto Taricco
}

A Neurocirurgia tem como peculiaridade a complexidade da especialidade exigindo alta tecnologia e costuma ser um trabalho em equipe.

Para se tornar especialista em Neurocirurgia é necessário fazer a residência médica em Neurocirurgia que tem duração de 5 anos.

Os locais para fazer a residência médica em Neurocirurgia são oficializados pela Sociedade Brasileira de Neurocirurgia (SBN) e, ou pelo Ministério de Educação e Cultura (MEC). São 54 serviços credenciados até o momento, sendo somente um, em Recife, localizado no Nordeste. Todos os demais estão na região sudeste e sul do país. Esse fato explica o grande número de candidatos que vem para a região sul e sudeste do Brasil para prestar as provas para residência.

Como já dissemos a residência médica em Neurocirurgia tem duração de 5 anos, sendo o primeiro ano dedicado a Neuroanatomia, Neurofisiologia, Neurologia clínica e Intensivismo em Neurologia. Os residentes são submetidos a provas anuais, que são realizadas em todo o pais, no mesmo dia e mesmo horários, que é na primeira sexta feira do mês de dezembro às 14:00 $\mathrm{h}$. A nota mínima é seis, e o aluno reprovado tem a oportunidade de prestar outra prova no meio do outro ano. Após os cinco anos de residência, se foi aprovado nas provas anteriores, realizará uma prova teórica e oral final.

Os colegas que realizaram residência em outro país, terão que apresentar documentação que comprove a semelhança do programa que realizou e terá que prestar a prova teórica e oral.

Na Disciplina de Neurocirurgia da FMUSP, são seis vagas por ano, desde 2011. Os residentes são submetidos a provas trimestrais, com nota mínima de sete. No caso de não aprovado tem a oportunidade de prestar nova prova de recuperação. Caso não consiga aprovação na segunda tentativa é desligado da Disciplina.

Pelas características da própria especialidade a residência é bastante desgastante, tanto fisicamente como emocionalmente, devido ao quadro clínico dos pacientes que exige condutas rápidas e precisas.

Ao terminar a residência as opções são em dar plantões em Serviços de emergência, geralmente em Hospitais públicos, e ser convidado a participar de alguma equipe já formada. Devido à complexidade da especialidade, ela tem suas sub-especialidades exigindo uma dedicação maior do profissional, com a realização de novos cursos e atualização permanente.

Avaliando o que foi colocado pode parecer que não haverá campo profissional, mas o que se nota todos os anos é que os residentes formados pela Disciplina de Neurocirurgia da FMUSP sempre tem uma colocação no mercado de trabalho.

E dependendo da sua vida profissional conquistará seu espaço e ter sucesso profissional.

Economicamente podemos afirmar que a Neurocirurgia é semelhante às outras especialidades médicas, exigindo uma dedicação muito grande.

O fundamental é gostar da especialidade. $E$ para ter uma apreciação como aluno, sugerimos que frequentem a Liga de Neurocirurgia para um conhecimento melhor da especialidade.

Graduado em Medicina pela Escola Paulista de Medicina - 1974, Residência Médica em Neuropsiquiatria e Neurocirurgia pelo HCFMUSP, Doutorado e Livre-docência pela FMUSP, Prof. Doutor do Departamento de Neurologia da FMUSP. Membro da equipe DFVNeuro das Sociedades Brasileira de Neurocirurgia, American Spine Injury Association, North American Spine Society, Sociedade Brasileira de Estudos da Lesão Medular, American Association Neurological Surgeons, World Federation of Neurosurgical Societies e Sociedade Brasileira de Patologia da Coluna Vertebral. 